\title{
SuPPly CHAIN MANAGEMENT OF RICE IN INDIA: A Rice Processing Company's Perspective
}

\author{
Vishal Sharma ${ }^{1}$, Dr. Sunil Giri ${ }^{2}$ and Siddharth Shankar Rai ${ }^{3}$ \\ ${ }^{1}$ Research Scholar, College of Management, SMVD University, Katra, J \& K, India \\ vishalsharma027@gmail.com \\ ${ }^{2}$ Faculty, College of Management, SMVD University, Katra, J \& K, India \\ drsunilgiri@gmail.com \\ ${ }^{3}$ Research Scholar, College of Management, SMVD University, Katra, J \& K, India \\ siddharthsr@hotmail.com
}

\begin{abstract}
The paper deals with the practical issues which exist in the supply chain of rice. The paper discusses various issues related to collaboration at downstream end of the supply chain, inventory management, demand consolidation and inventory reduction. While dealing with the supply chain issue it also gets into deal with the various procurement issues and finally a re-designed supply chain model has been proposed.
\end{abstract}

\section{KEYWORDS}

Demand Consolidation, Collaboration, Milk Run Routing System, Inventory Management, Supply Chain Redesigning

\section{INTRODUCTION}

Rice is the basic grain consumed as a food in India which is found in almost every Indian kitchen. It is the most common grain and the most common food in India, however, India is not only a big consumer of rice but also it is the second largest producer of rice in the world after China. India also holds the largest agriculture land for paddy production in the world. In 2009 total arable land for paddy in the world is 158300068 hectare with the total production of 685240469 tonnes of paddy, out of which 41850000 hectare of the area is held by India only, which produced 133700000 tonnes of paddy just second after 196681170 tonnes by China. India leads in terms of the land holding, while the production is led by China. The smallest paddy production and arable land both is claimed by the Russian Federation with 912970 tonnes and 177500 hectares respectively with second lowest figure of Iran (Source: Directorate of Economics and Statistics, Department of Agriculture and Cooperation).

A time series statistics by 'Indiastat.com' from 1949 to 2010 shows, that India over a period of time has grown in the total agriculture land and the production of rice. The statistics shows the continuous growth for area, production and the yield of rice, however in recent years it has shown a little bit of decline, which should be considered seriously and the necessary measures must be taken to keep it again on the growing track. But over the period of time it has shown a growing trend which we can interpret that India has grown in terms of rice producing land from 30.5 million hectare and 23.5 million tonnes of rice production with an yield of $771 \mathrm{~kg}$ per hectare in 1949-50 to 41.92 million hectare agriculture land for rice, 89.09 million tonnes of produced rice and $2125 \mathrm{~kg}$ per hectare yield in the year 2009-10.

India is not only known for its production, but it is also one of the biggest consumers of rice in the world Figure 1 shows its domestic consumption while making it clear that most of its total rice supply is consumed in India. With the help of a time series data from $1960-2012$, the statistics of the figure shows that in year 1960 the domestic consumption of rice was 35473 
thousand metric tonne on the supply of 38040 thousand metric tonnes rice, which increased in the year 2012 after a long growing trend to 95250 thousand metric tonnes of domestic consumption on a supply of 124100 thousand metric tonnes of rice.

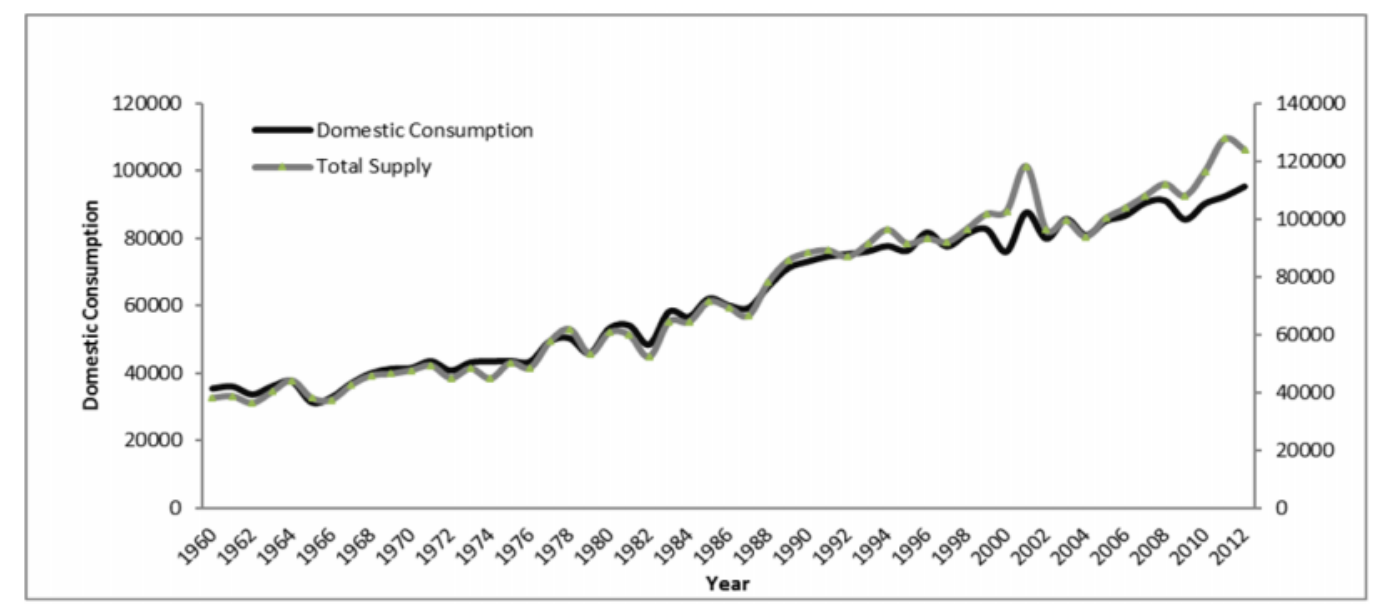

(Source: www. indexmundi.com)

Figure 1: Total supply and consumption of rice in India from 1960-2012

The economics of rice in India including production, supply, consumption and yield, along with the agriculture land for paddy farming has continuously shown a growing trend for a period of time, however, with lots of fluctuations and inconsistency. After a growing trend it has shown a declining trend in all these areas in the recent time which is the time of global change. And it can be interpreted as a negative sign if it is about the coping up of the rice industry with changing scenario. Ballabh and Pandey [1] while studying the two villages in India observe the slow agricultural growth of rice as a major issue and emphasise on the new opportunities on increasing the productivity and speeding up the agricultural growth.

Shergill [2] find in a study that production of rice in India is questionable on economic and ecological grounds. The decline is the concern of study and it can be either due to the technological obsolescence, the production, distribution, and the issues of market, or all of these issues. All these issues form it as a concern of the supply chain management, which is defined as a philosophy [3] which study the entire flow of material and goods throughout the channel in an integrated way, starting from supplier to the end customer. It is an integration of three or more establishments whose activities are interlinked together directly with a purpose to flow the products, services, finances and information either in upstream or downstream way between the end customer and the source [4]. One can say that for proper functioning of the rice sector in the agriculture industry, and regaining its upward growing trend it is necessary to resolve its supply chain problems, and hence a complete study of the rice supply chain management and its reengineering is essential.

\section{SUPPLY CHAIN OF THE RICE INDUSTRY}

As rice is the basic grain of daily consumption in India, it always has the significant demand which shows a seasonal growing trend especially at the time of festivals and during the seasons of cultural events. To identify the appropriate demand and meet them properly in a profitable way is primary concern of rice supply chain. A proper supply chain management framework is very essential for efficient sourcing, processing, distribution, and retailing and hence meeting the customer demands without facing a situation of lost sales. Production and business of rice has been one of the most traditional and major concerns of Indian Economy, but still no proper supply chain framework for it has been developed, which very often causes unfulfilled demands, 
stock outs and overstocking, and distribution issues. The main reason behind not getting proper attention is, rice industry has always been treated as the subject of Agricultural Economics and never became able to portray itself as a topic of supply chain studies. Most of its operations are very traditional which need to be reformed if it has to gain competitive advantage in the era of globalisation.

A traditionally followed basic framework for rice supply chain management generally follows the multi stage supply chain system including: Farmers as the basic supplier of paddy, middlemen or agents, rice processing industries, distribution agents, and retailers; as the interlinked upstream and downstream stages. During the long supply chain process many activities take place at every stage which affect the function of next stage and requires it to co-operate in the customised manner. To understand the detailed process, the study describes a detailed supply chain framework, as shown in 'Figure 2', which explains the complete supply chain activities currently being practiced in the rice sector. The process clearly explains where the supply chain requires the intermediaries and where it is sourced and distributed directly to the next major stage.

Primary stage of the rice supply chain is held by the paddy farmers who supply paddy to the rice processing companies, which is supplied both directly and through intermediaries, depending on the type of farmers and their productivity. The farmers may be categorised in two types as: large land holding farmers and the Small land holding ones, on the basis of the land they own, their production capacity and reachability to the market. Large Land Holding Farmers involved in organised production from business point of view who produce on very large scale and, the second type of farmers which are Small Land Holding Farmers, working on small farms in villages, whose productivity is low, and can spare very low amount of paddy after keeping the year's stock for their own use. Based on the kind of production they are involved into; they are divided into two types: Organic Farmers, those who are involved in organic farming where cultivation of the paddy is based on the use of green manure, compost and the approved natural substances while without any use of the manufactured chemicals, fertilizers, and pesticides including the insecticides, fungicides and the herbicides. Secondly, Inorganic Farmers are those who use the manufactured chemicals, fertilizers, and the pesticides for cultivation of paddy.

Both the farmers with large land holding and the ones with small land holdings use same kind of strategy with the distribution of organic crops of paddy, as they are directly sent to the rice processing company without involvement of any intermediary. These crops are produced on the special demands and orders from rice processing companies. As it is produced on no pesticides and chemicals it has low productivity and high cost and thus produced on the orders. The totally natural process of production which uses natural contents only, at every stage of the production of crop; also requires the produced paddy must not contain any sign of the chemicals and pesticides and hence requires the continuous monitoring and control measures, which makes it necessary for the rice processing company to directly procure the organic paddy from farmers irrespective of their land size without involving any middleman. On the other hand the process for inorganic farmers is different based on their land sizes. The rice processing companies adopt the different supply chain strategies with both large land holding farmers and the smaller ones in order to source the paddy.

Large land holding farmers most often directly supply their paddy to the rice processing companies which reduces their middlemen cost and increases the revenue. Rice processing companies also find it profitable to source directly from the farmers as it reduces their procurement cost, logistics cost, intermediary cost and the supply chain cost. However in some instances the Paddy farmer with large land holding, are not able to directly supply the inorganic paddy because of: low demand, or the quantity supplied in bulk has not covered all the quantity of paddy prepared for sales, or paddy has been stored to be sold in lower quantities in different seasons to generate more revenue, or some other reasons. Therefore, they require following an indirect mode of distribution generally through various forms of intermediaries for the sale of their paddy. 
Supply chain process is not as direct for the small land holding inorganic farmers. Inorganic farmers with small land holding either sell their paddy in 'Mundi', a marketplace in the town areas where the small farmers of nearby villages sell their yields from farms and the processing units purchase the grains and vegetables from, either directly or through agents, which is considered as a convenient place for the small paddy farmers to sell and also for rice processing companies to procure. Or, in another way the rice processing companies procure the paddy through Middlemen or Agents, who purchase the paddy from small farmers in small quantities and then sell them in bulk to the rice processing companies. Direct procurement is not profitable for the rice processing companies from the small farmers, as their cost of logistics and supply chain will be very higher comparatively the cost of sourcing through 'Mundies' and 'Agents'.

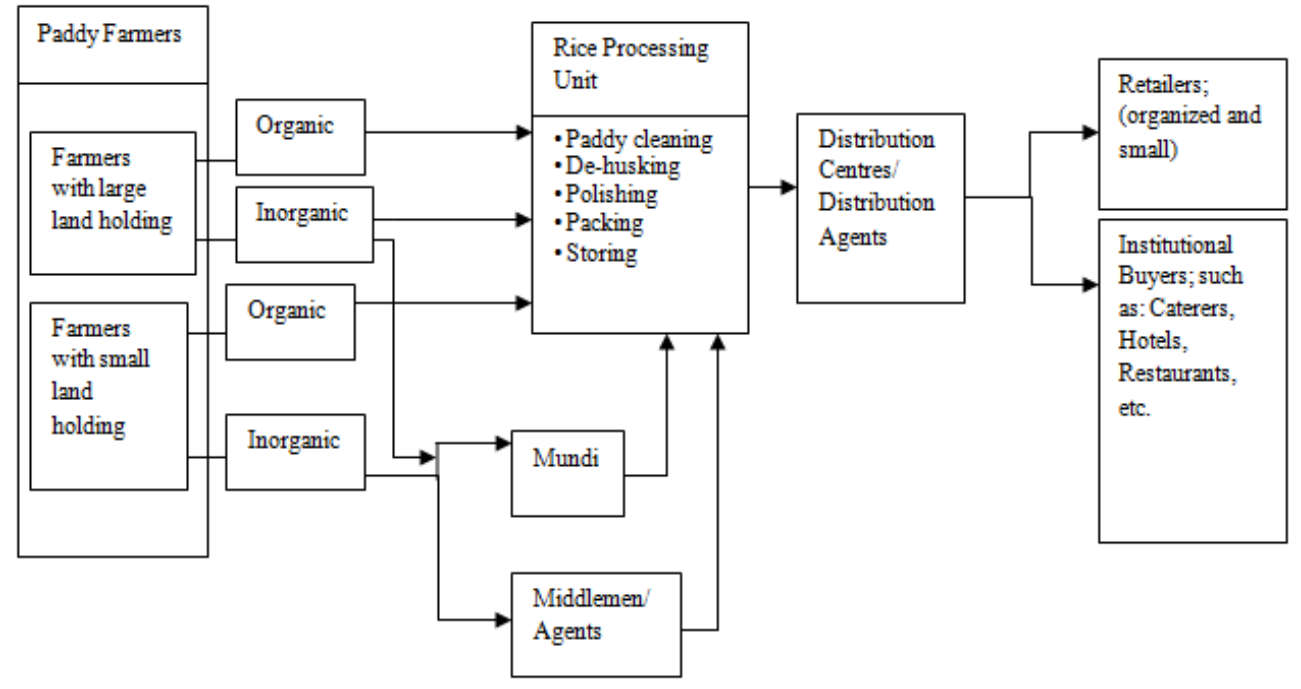

Figure 2: Detailed rice supply chain process

The operations process of rice processing unit involves: 'Paddy cleaning', where straw, weed seeds, soil and other inert materials are removed from paddy; 'De-husking', where the husk layer is removed from paddy by friction, also known as 'De-hulling'; 'Polishing', the process where white rice is produced in two forms: full length and broken, after removing the bran layer and the germ, and finally it goes through the process of 'Packing', after which it is stored for distribution. After operations process the rice is finally distributed to the 'Retailers' or directly to the 'Industrial Buyers', through the 'Distribution Centres' or 'Distribution Agents'.

The traditionally practiced supply chains lack in efficiency due to one or more reasons, out of which major issue is the existence of many intermediaries existing between the farmer and the rice processing company, and again between the processing company and the customer, resulting in greater complexity, lower efficiency, reduced margin and increased cost on the product [5]. Supply chain management also requires the mutuality and co-operation among its upward and downward members [6] where especially the rice supply chain in India is lacking. Vlachos and Bourlakis [7] describe with reference to food supply chain that how effective collaborative supply chain is and how it is very important to build trust and collaboration among all the partners. For any supply chain it is important to understand the nature of product and then designing a supply chain according to its nature [8]. There are two basic types of products in general i.e. Functional and Innovative with their appropriate matching supply chains as efficient and responsive respectively [8].

Demand of rice for a period of time doesn't change dramatically and it can be predicted easily, and profits earned are very marginal, which make it a functional product in nature, and therefore it requires to have an efficient supply chain. An efficient supply chain requires proper forecasting 
of customer demand [9], if lacking, it will result in stock outs of demanded and overstocking of undemanded variety of rice. Indian rice sector is very much lacking in forecasting at all the levels, starting from which variety to produce, to which variety to order and source at which time. Proper interchange of data and a sound information technology based system is vital for the success of any supply chain for achieving the competitive advantage, [10] lacking in which may result in various supply chain problems of supply chain, such as visibility problem [11] and bullwhip effect [12], which is the very common problem in Indian rice sector. Therefore it is very important to get the information which is on time and right [10], and shared at all the levels among the members of the supply chain [13].

\section{RELATED STUDIES}

Oden [14] \& Diarra et al [15] in a study of supply chain of rice has described various stages, structure, and reforms in production and distribution of rice during pre-liberalization and postliberalization periods in Mali. Wong et al. [16] in the study of supply chain management of Malaysian paddy and rice industry, has presented an overview of rice supply chain, with various challenges faced and reforms needed in Malaysian rice and agri-food industry. While reviewing the marketing and logistics strategies by various rice mills in Odisha, India Rath et al. [17] emphasises on a sustainable logistics and distribution model for the modern rice mills in India. Ahumada, and Villalobos [18] in a study of agri-food supply chain, describe the production and distribution model of agri-foods which is based agricultural crops.

Lowe and Preckel [19] characterize the agri-food supply chain as the ones with the long lead times and misalignment and uncertainty between their demand and supply. Achchuthan and Kajananthan [20] in a study of value chain of paddy sector in Sri Lanka describes the strengths, weaknesses, opportunities and threats among the various supply chain and marketing players in this sector and explores various challenges to overcome to make Sri Lanka a better place for paddy production and distribution. Simatupang and Timmer [21] describe the rice production, its growth and challenges and suggest the improvements in their study of Indonesian rice production. Wiboonpongse and Sriboonchitta [22] describe about various traditional and modern rice production, distribution and retailing structures and its players in Thailand, while exploring the supply chain, distribution and marketing strategies.

Hajjdiab and Taleb [23] describe about the development of agile software to make supply chain more responsive and more traceable. Bechini et al. [24] emphasize on using the IT tools and web services in collaborative practices to make the supply chain more traceable. Laosirihongthong et al. [25], Schuster et al. [26], Gaukler [27], Brintrup et al. [28], and Myerson [29] describe about using and implementing RFID in supply chain to increase its visibility and traceability of inventory in the entire supply chain to enhance the collaborative practices.

\section{Rice Supply Chain REDESIGNING}

As the traditional supply chain is not efficient and competitive with the changing global scenario, a redesign in the supply chain management system of rice sector is demanded. It must need to work on the areas of efficiency which requires looking into a collaborative framework, Information management, forecasting of future requirements and inventory planning and an efficient logistics system. It also requires minimising the role of intermediaries to the minimum possible level.

\subsection{Collaborative framework}

A collaborative framework with the help of information management tools which requires interchange of data between the rice processing companies and retailers; is very necessary from the co-ordination point of view and meeting the customer demands efficiently without bearing the risk of unsatisfied customer and loss on sales. Information plays a very important role in the 
collaborative structure of the supply chain, and hence information management is vital at all the stages of the supply chain [30], in the age of information [31]. Improper management of information may result in 'Bullwhip Effect' i.e. variability of inventory planning and forecasting at different levels of supply chain, which may lead to overstocking or stock outs of the inventory.

Rice processing unit and the retailer must share their information with each other in order to collaboratively forecast and plan the inventory. A well designed collaborative framework as shown in Figure 3 is required to increase the efficiency of the supply chain in rice sector. The collaborative framework describes how information flows between the rice processing company and the retailer, in order to collaboratively plan and forecast the inventory.

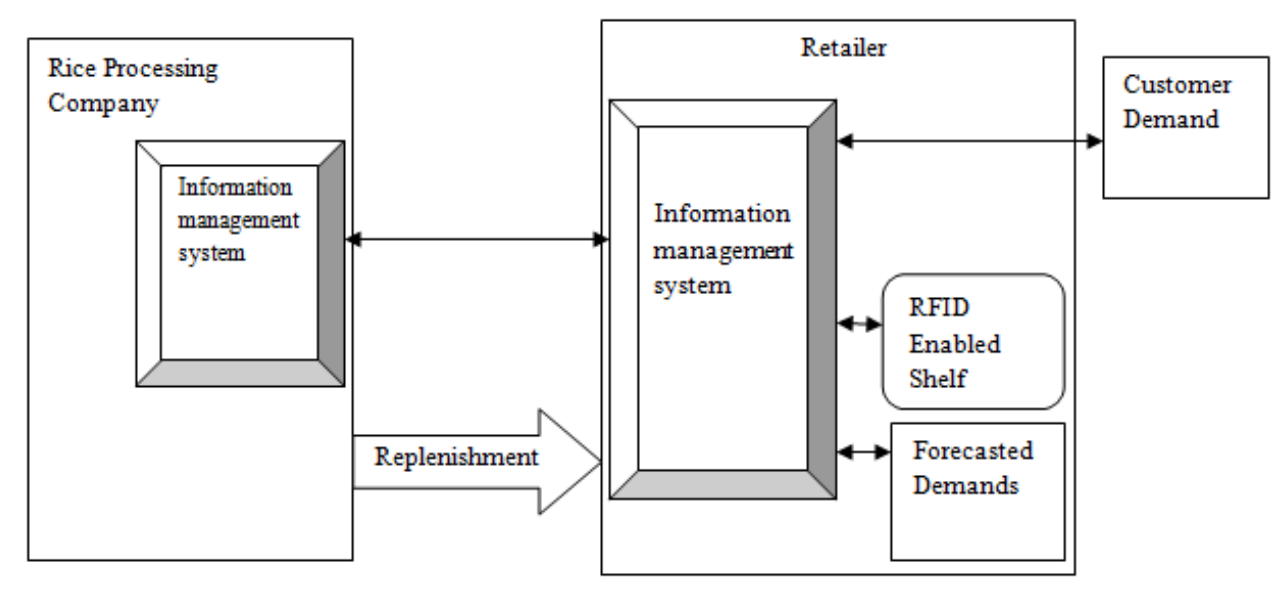

Figure 3: Collaborative framework

Information system of the retailer, which have the information of the customer demand, information of inventory level on the shelves with the help of RFID system, and forecasted demands; shares all the information with the information system of the rice processing company. After analysing the information and collaborative planning, the rice processing company replenishes the required variety in the planned predetermined quantity to the retailer.

\subsection{Inventory Management}

Dealing with the inventory is a major issue in the supply chain management system of the rice sector. The traditional supply chain in the rice sector in India has always confronted the challenge of availability of the right inventory. Inventory management in rice supply chain requires proper forecasting of demand, inventory planning, and procuring of the inventory at the right time. Customer demand of the different varieties of rice for the whole season or year should be forecasted in advance while considering all the fluctuations because of festivals and social and cultural events.

However, it may not be necessary to keep inventory for all the forecasted varieties of rice, as they may occupy the rice processing unit's storage capacity and block the space for some variety of more demand. In practice it has been found that many of the rice processing units are loaded with high inventory which is due to a large number of variants irrespective of their demand, which results in overstocking of the varieties with lower demand and stock outs of the varieties with higher demand.

The rice processing company in this case should drop the processing of the varieties carrying comparatively lower demand say up to 5\% of total demand over the period of a time. Processing and stocking these varieties blocks the space for other demanded varieties as their movement is 
slow. While not processing and keeping these varieties will free the space and room for the rice varieties which are really in demand. However, not to disappoint the customers of these varieties and to maintain the relationship with them, the rice processing company should collaborate with the hullers where they will source these varieties from, on the specific customer demands.

Rice processing companies are suggested to adopt the consolidating demand approach. The approach suggests processing all the nearby demands of same kind of varieties together for gaining economies of scale and reduction in inventory of finished goods which are kept otherwise.

\subsection{Procurement}

Procurement of the paddy by the rice processing company requires a differentiated approach, as varieties of paddy are seasonal in some parts of country while on the other hand in some parts of country paddy is cultivated three times a year. The rice processing company should forecast collaboratively with the help of retailer for the optimum demand of the rice which must be consumed during the year, and should procure the planned paddy at the time of season of rice production in the whole country. The reason behind is, at that time because of the production of rice in the whole country the paddy will be available at the lowest price of the whole year. When the demand fluctuates and more quantity is demanded than forecasted, rice processing company can source the paddy from areas where there is still the season of paddy cultivation.

Seasonal forecasting and procurement is also very essential as some of the varieties of paddy are seasonal and geography specific. For the procurement of these varieties the paddy processing company should forecast their whole year's demand and procure them in their season in the particular geography. Procurement of these varieties of paddy in the off season may result in higher cost to the rice processing company.

Another approach of procurement should be made on the basis of nature of cultivation of the paddy. While procuring the organic paddy, the rice processing company should properly monitor and control the whole paddy cultivation process. It should closely watch and monitor the whole process from seeding, manuring, and till the harvesting because any effort from the farmer to increase the yield may result in pesticide and chemical content in the paddy. In the same way some parameters and monitoring for the inorganic production is also required because, failing to which may result in excessive content of pesticide and chemical in the paddy because of the farmer's effort to gain more yield, which is neither good for customer's health nor it is for the business of company in the long run. Excessive use of pesticides may also make the land barren or infertile for few years and rice processing company may face the problem of non-availability of raw materials.

\subsection{Logistics System}

An efficient logistics system can improve the efficiency of a supply chain, while a bad logistics system will make its situation worse. Rice supply chain in India is facing a major challenge of on time inventory availability and high logistics cost. To cope between the logistics costs and on time delivery is a big challenge. Either inventory delays from its delivery time or it causes higher delivery cost than which the rice processing unit has estimated to pay. The rice processing company is required to minimise its both inbound logistics expenses and the outbound logistics expenses while reducing the transportation delays. The solution of the problem lies in the efficiency of transportation system and reducing the number of intermediaries. The company should design its transportation very efficiently in case of their transportation system. On the other hand in case of the third party logistics also there must be the proper collaboration between the logistics service provider and the company hiring the services.

Reduction in the number of intermediaries to the minimum is also suggested for the efficient logistics system. More number of intermediaries results in the movement of paddy to more places 
and centres. It increases the delivery time, transportation delays and transportation cost; which leads to inefficiency of the logistics system. To recover from the problem the rice processing company should minimise the number of intermediaries. It should take direct deliveries from the big farmers where it will get the paddy in bulk. On the other hand it should make its own procurement centres where without the involvement of any agent or intermediary the paddy farmer will sell his paddy directly. The same process should also be adapted in the case of downstream supply chain where the bulk amount of rice will be distributed directly to the big retailers and institutional buyers.

On the other hand in the case of small retailers rice will be distributed through the company owned local distribution centres. Small retailers place their orders to the distribution centre and through this; it will reach to the processing unit which will deliver it the consolidated demanded rice of all the small retailers in the area covered by the distribution centre. From the distribution centre it is suggested to distribute the rice through the 'Milk Run Routing System' as shown in Figure 4.

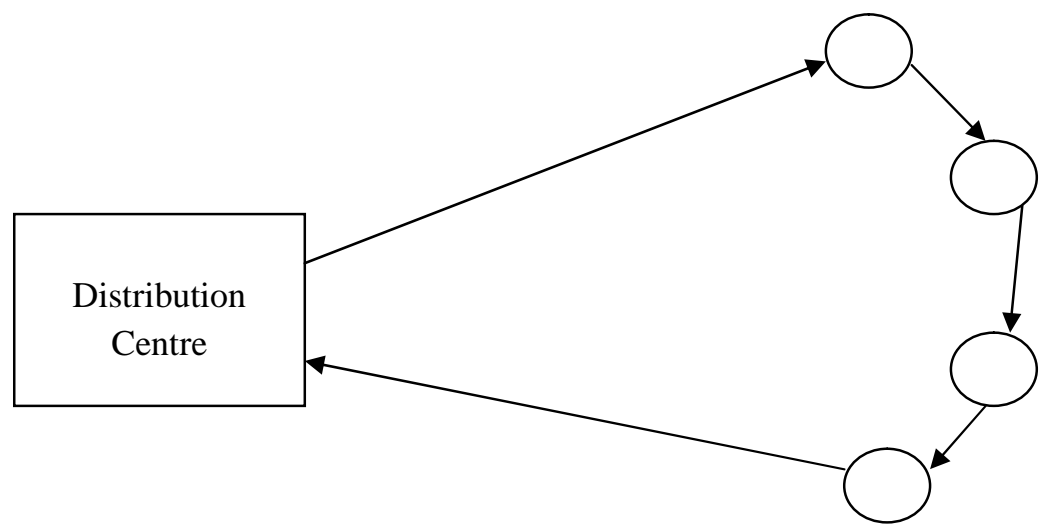

Figure 4: Milk run routing strategy for small retailers

The milk run system suggests picking truck load inventory from the distribution centre and delivering it to various retailers according to their demand. For example: The truck load capacity of 120 tonnes and there are orders from four small retailers of various quantities. The truck will go from distribution centre to the first retailer, will deliver its order, then will go to the second retailer and in the same way will go to the other retailers also until it is completely unloaded. Once unloaded, the truck will return to the distribution centre. The process continues with many numbers of trucks and many small retail orders. The strategy is appropriate with the small retailers because delivering them individually will not utilize the truck loading capacity and will incur extra costs on the company, while adopting it will reduce the supply chain cost and the delivery time.

An improved redesigned supply chain framework argues about minimising the unnecessary members of supply chain, such as, lot of intermediaries at both upstream and downstream front, and supports the direct interaction with the stages and members of the supply chain as shown in 'Figure 5'. The redesigned supply chain framework argues about the two way flow of information in the whole supply 


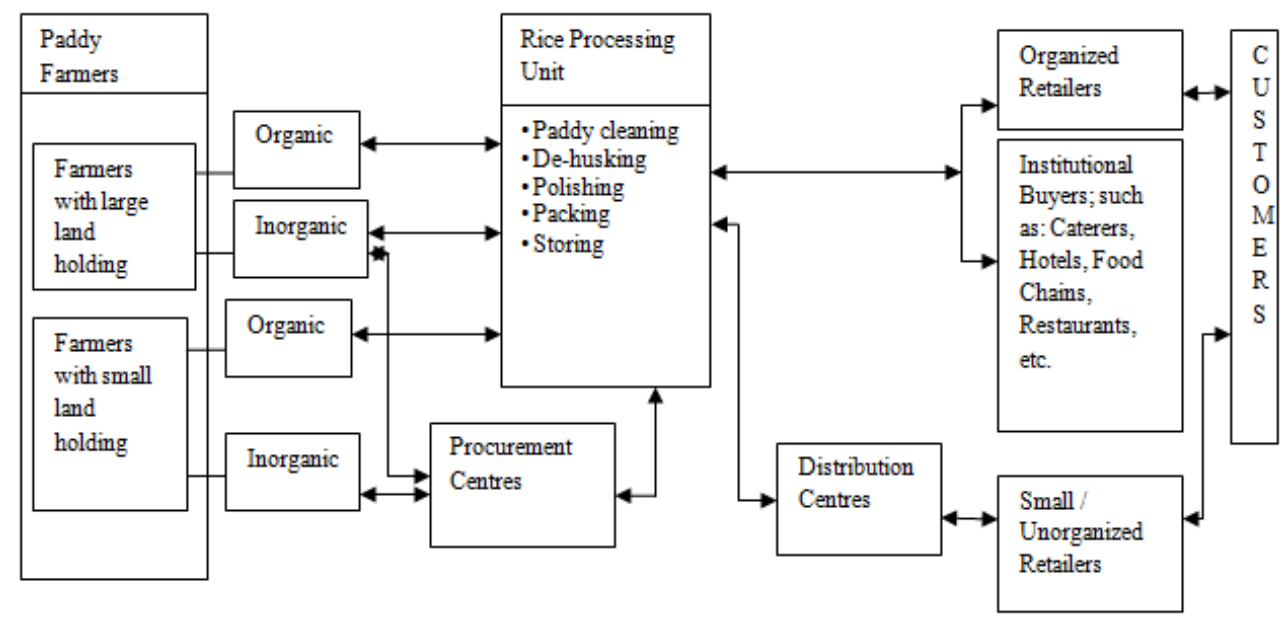

Figure 5: Redesigned supply chain management framework

chain in lieu of keeping the flow one way as adopted by the traditional rice supply chain model, where the information flows in one backward way and then the material flows in the forward way. In the new supply chain model the rice processing company shares information directly with the large land holding paddy farmers and the organised retailers and institutional buyers. Whereas in the case of small retailers and small land holding farmers it takes the help of company owned distribution centres and procurement centres to share the information with them. The organic paddy from both the large land holding farmers and the smaller ones is distributed directly to the rice processing company. In case of inorganic paddy the small land holding farmers supply it through the procurement centre whereas, the large land holding inorganic paddy farmers generally supply the paddy directly, however in some cases through the procurement centres also.

In the same way the distribution centre is developed to deal with the small retailers as their direct dealing will result in higher supply chain costs. These centres work as medium of information and material flow among these small players and the rice processing company. Establishing company owned centres instead of the intermediaries reduces the supply chain cost, increases transparency, increases visibility, increases supply chain speed and controlled supply chain operations. Procurement centres for sourcing paddy from the small farmers instead of sourcing through 'Mundi' and 'Agents', generates more revenue and hence profitable to both the farmer and rice processing company, while reducing the intermediary cost and commissions, supply chain cost, increasing visibility of operations and an established relationship directly between the farmer and the company. In the same way at the down end the rice processing reduces its distribution cost by directly supplying the rice to organised retailers and the institutional buyers, and on the other hand it finds more feasible to set up its own distribution centre to deal with the small retailers rather than dealing through the distribution agents. It is also not suggested to supply them directly because they purchase in the smaller quantities and it will increase the company's logistics cost to very high.

\section{CONCLUSION}

The food grains are the critical requirement for human survival. The availability needs to be backed by availability at affordable price and adequate quality. The availability may be assured by production as well as reduction of wastage. The same applies to rice also. To remain competitive the rice processing unit needs to adopt the latest supply chain strategies. They need to focus on co-ordination, collaboration with farmers and customers for smooth flow of processed rice. Demand consolidation will help in inventory reduction. Focus has to be made on distribution 
channel design. It is essential to redesign the supply chain of rice for better performance of a company as well as better service to the customers.

The present supply chain structure of rice in India works on the traditional framework which involves many intermediaries at supply and distribution fronts. The current supply chain structure of rice in India is somewhere lacking in efficiency and needs reforms. The traditional supply chain structure faces the problems of inventory management, where either there is the overstocking which results in obsolescence and increased supply chain costs, or the stock outs of the demanded varieties resulting in lost sales. Supply chain of rice in India is also facing the supply chain problems related to procurement, distribution, intermediaries collaboration, and logistics system which needs to be redesigned. A proper framework which suggests the mechanism for tracing and visibility of inventory in the system, procurement and sourcing of paddy, operations of the rice processing companies, distribution system, retailing strategy, and logistics system is very essential in order to make the Indian supply chain efficient and globally competent. In spite of being the second largest producer in the world and a big consumer of rice which holds a significant presence in the global agri-food market, India fails to contribute to the global food business to the level it deserves.

The study considers the various small and big players at every stage of the supply chain, and rather than using the same supply chain practices and strategies regardless of their size and area of operations, it suggests various structures and strategies for sourcing, procurement, collaboration, and distribution including the logistics strategies for the supply chain member at every stage according to their nature, type, size and format of working.

\section{ACKNOWLEDGEMENT}

I want to show my all the gratitude to my parents, only because of their blessings I am here. I also want to show my gratefulness to my 'Mentor', my 'Guru' Dr. Sunil Giri, who has taught me everything in supply chain management, and whose knowledge reflects from my every writing. I am also very thankful to my research scholar friends who have always been with me.

\section{(Siddharth Shankar Rai)}

\section{REFERENCE}

[1]. Ballabh V. and Pandey S., (1999), Transitions in Rice Production Systems in Eastern India Evidence from Two Villages in Uttar Pradesh, Economic and Political Weekly, Vol. 34, No.13, pp. A-11 - A16

[2]. Shergill H. S., (2007), Sustainability of Wheat-Rice Production in Punjab: A Re-examination, Economic \& Political Weekly, Vol. 45, No.52, pp. 81-85

[3]. Ellram, M. Lisa, \& Cooper, C. Martha, (1990) "Supply chain management partnerships, and the shipper- third party relationship", International Journal of Logistics Management, Vol. 1, No. 2, pp. 1 - 10 .

[4]. J. T. Mentzer, W. Dewitt, J. S. Keebler, S. Min, N. W. Nix, D. C. Smith \& Z. G. Zacharia, (2006) "Supply Chain Management", (5th ed.). California: Sage Publications, Inc.,

[5]. Lin P. C. and Wu L. S. (2011), How supermarket chains in Taiwan select suppliers of fresh fruit and vegetables via direct purchasing, The Service Industries Journal, Vol. 31, No. 8, pp. 1237-1255

[6]. Maloni, M.J., \& Benton, W.C. (1997). Supply chain partnerships: Opportunities for operations research. European Journal of Operational Research, 101(3), 419-429.

[7]. Vlachos, I., \& Bourlakis, M. (2006). Supply chain collaboration between retailers and manufacturers: Do they trust each other? Supply Chain Forum - An International Journal, 7(1), 7080. 
International Journal of Managing Value and Supply Chains (IJMVSC) Vol. 4, No. 1, March 2013

[8]. Fisher M. L. (1997), What is the right supply chain for your product, Harvard Business Review, Vol. 75, No.4, pp. 105- 116

[9]. Fisher M. L., Raman A., and McClelland A. S. (2000), 'Rocket Science Retailing is Almost HereAre You Ready?', Harvard Business Review, Vol. 78, No. 4, pp.115- 124

[10]. Tavassoli S., Sardashti M., Toussi N. K. N., (2009), 'Supply Chain Management and Information Technology Support', IEEE Conference, pp. 289-293

[11]. Bartlett P. A., (2007), 'Improving Supply Chain Performance Through Improved Visibility', The International Journal of Logistics Management', Vol. 18, No. 2, pp: 294-313.

[12]. Metters R., (1997), 'Quantifying the bullwhip effect in supply chains', Journal of Operations Management, Vol. 15, No.2, pp. 89-100.

[13]. Brau, J.C., Fawcett S.E., Magnan G.M., and McCarter M.W., (2005), "Information Sharing in Supply Chain Management: A Two- Dimensional Perspective," Working paper, University of Illinois Urbana-Champaign.

[14]. Oden L., (2011), Efficiency of the rice market channel in the Office Du Niger, Minor Field Study Series: Department of Economics at the University of Lund, No. 211

[15]. Diarra, Salifou B., Staatz, John M., Bingen, James R., Dembélé, and Niama N., 1999, “The Reform of Rice Milling and Marketing in the Office du Niger: Catalyst for an Agricultural Success Story in Mali”, Department of agricultural economics, Michigan State University, Staff paper no. 99-26.

[16]. Wong L. C.Y., Suraya A. Emrus, Bashir B. M., and Tey J. Y.S., (2010), Malaysian Padi \& Rice Industry: Applications of Supply Chain Management Approach, National Rice Conference Swiss Garden Golf Resort Lumut, 28-30 June.

[17]. Rath B., Mangaraj B. K., and Mishra B. P., (2012), Fuzzy Logic Based Simulation for Modeling of Sustainable Marketing Policy for Modern Rice Mills in Odisha, International Journal of Supply Chain Management, Vol. 1, No. 3, 34-42.

[18]. Ahumada O., and Villalobos J. R., (2008), Application of planning models in the agri-food supply chain: A review, European Journal of Operational Research, 195, 1-20

[19]. Lowe, T.J., Preckel, P.V., 2004. Decision technologies for agribusiness problems: A brief review of selected literature and a call for research. Manufacturing \& Service Operations Management, Vol. 6, No. 3, pp.201-208.

[20]. Achchuthan S., and Kajananthan R., (2012), A Study on Value Chain Analysis in Paddy Sector: Special Reference to Kilinochchi District, Sri lanka, Global Journal of Management and Business Research, Vol. 12, No. 18. pp. 13-22.

[21]. Simatupang P., and Timmer C. P., (2008), Indonesian rice production: policies and realities, Bulletin of Indonesian Economic Studies, Vol. 44, No. 1, 65-79.

[22]. Wiboonpongse A., and Sriboonchitta S., (2004), Regoverning Markets: Securing Small Producer Participation in Restructured National and Regional Agri-Food Systems in Thailand, Chiang Mai University, Thailand.

[23]. Hajjdiab H., and Taleb A. S., (2011), Adopting Agile Software Development: Issues and Challenges, International Journal of Managing Value and Supply Chains (IJMVSC), Vol. 2, No. 3, pp. 1-10.

[24]. Bechini A., Cimino M. G.C.A., Marcelloni F., Tomasi A., (2007), Patterns and technologies for enabling supply chain traceability through collaborative e-business, Information and Software Technology, Vol. 50, No.4, pp. 342-359.

[25]. Laosirihongthonga T., Punnakitikashemb P., and Adebanjo D., (2013), Improving supply chain operations by adopting RFID technology: evaluation and comparison of enabling factors, Production Planning \& Control: The Management of Operations, Vol. 24, No.1, pp.90-109

[26]. Schuster E. W., Allen S. J., Brock D. L., (2007), Global RFID: The Value of the EPCglobal Network for Supply Chain Management, NY, Springer. 
International Journal of Managing Value and Supply Chains (IJMVSC) Vol. 4, No. 1, March 2013

[27]. Gaukler G. M., (2011), RFID Tag Cost Sharing in the Retail Supply Chain, Journal of Organizational Computing and Electronic Commerce, Vol. 21, No. 4, pp. 315-331

[28]. Brintrup A., Ranasinghe D., \& McFarlane D., (2010), RFID opportunity analysis for leaner manufacturing, International Journal of Production Research, Vol. 48, No.9, pp.2745-2764

[29]. Myerson J. M., (2007), RFID in the Supply Chain: A Guide to Selection and Implementation, FL, Auerbach.

[30]. Lambert D. M.; Stock J. R.; Ellram L. M., (1998), 'Fundamentals of Logistics Management', Boston, McGraw- Hill.

[31]. Levi D. S., Kaminsky P., Levi E. S., and Shankar R., (2011). Designing and Managing the Supply Chain, N D: TMH.

Directorate of Economics and Statistics, Department of Agriculture and Cooperation. http://eands.dacnet.nic.in/

Indiastat. www.indiastat.com

Index mundy. www.indexmundi.com 